\title{
Design and Analysis of a Novel Lightweight Translator Permanent Magnet Linear Generator for Oceanic Wave Energy Conversion
}

\author{
O. Farrok ${ }^{1}$, M. R. Islam ${ }^{2}$, Senior Member, IEEE, Y. G. Guo ${ }^{3}$, Senior Member, IEEE, and J. G. Zhu ${ }^{3}$, Senior Member, IEEE \\ ${ }^{1}$ Department of Electrical \& Electronic Engineering, Ahsanullah University of Science \& Technology, Dhaka-1208, Bangladesh \\ ${ }^{2}$ Dept. of Electrical \& Electronic Engineering, Rajshahi University of Engineering \& Technology, Rajshahi-6204, Bangladesh \\ ${ }^{3}$ Faculty of Engineering and Information Technology, University of Technology Sydney, Broadway, NSW 2007, Australia
}

\begin{abstract}
At present, most of the linear generators contain a heavy translator for harvesting wave power from the ocean into electrical power. As the translator is connected to the buoy, the buoy dynamic performance is reduced by the large mass and as a result low velocity of the translator would degrade the electricity generation of the linear generator. This problem has been minimized by the new design in this paper, where the translator is clipped off at first and split into two separate portions to minimize its weight and a secondary stator coupled magnetically with a special m-shaped main stator is used to flow the necessary magnetic flux. The weight of the proposed translator is $21.82 \%$ lower than the conventional one and $49.1 \%$ by using a recently available permanent magnet with higher specifications. The finite element method is applied for the analysis and comparison between the new and conventional designs with the aid of ANSYS simulation software. Different parameters of the existing and the proposed linear generator have been presented and compared. The simulation results show that the proposed one can generate the same amount of electricity as the existing one with almost half of the translator size. According to the mathematical model, it is understood that the dynamics of the translator would be higher for its lower mass and vice versa. Therefore, minimizing the translator size would result in decrease of mass, which increases the dynamics of the buoy connected to the translator.
\end{abstract}

Index Terms - Linear generator, m-shaped stator, split translator, secondary stator, wave energy converter.

\section{INTRODUCTION}

A LL THE traditional energy sources are running down A rapidly from which the electrical energy could be produced [1]. This fact has inspired the scientists in the last few decades to harvest electrical energy from renewable energy sources (RESs). The implementation of one of the nonconventional RES known as oceanic wave energy (OWE) along with the conventional RES can solve this issue while providing the future demand of electricity. The most attractive feature of the OWE is its availability of up to $90 \%$ of the time, which is nearly 3-4 times higher than the well-known conventional RES such as wind and solar energy. Another two advantages of the OWE include its predictability and having the highest energy density among the RESs [2].

The oceanic wave energy converter (WEC) can be on shore, near shore, and off shore depending on its physical existence in the ocean. Depending on the power take off (PTO) system, the WEC may be categorized into: (i) oscillating water column, (ii) overtopping device, and (iii) oscillating device. The oscillating device is basically a point absorber type wave energy device (WED) which has been already considered very effective [3]. These devices produce linear motion for the linear generator by capturing the wave power through a floating buoy. Such an arrangement is advantageous in the sense of bypassing the intermediate mechanical system [4]. The benefits of a double-sided flat rectangular linear permanent magnet synchronous generator have been explained in [5]. Another novel superconducting magnet excited flat linear generator for wave energy conversion system has been explained in [6]. Since the linear velocity of WED obtained from the oceanic wave is variable, the linear generator runs at irregular speed [7]. Different types of flat and tubular type linear generators have been investigated; almost all of them have a solid translator of steel cores with large mass [8]-[12].
According to the mathematical model, the vertical speed of any object with large mass is low due to its poor dynamics. As the buoy and the translator are connected together, heavy translator would have reduced dynamics, which results in low vertical speed and finally the less amount of electricity. Moreover, in permanent magnet linear generators, cogging force is one of the inherent difficulties producing mechanical vibration in vertical direction.

In order to deal with these problems, a new split translator supporting stator linear generator (STSSLG) is presented in this paper, where the translator is clipped off and split into two portions to reduce its mass. The magnetic flux that would flow through the translator is allowed to pass through a secondary part of the stator. The stator position vector diagram has been implemented in the proposed STSSLG for reducing the cogging forces and force ripples to avoid the complication in the mechanical architecture.

\section{ANALYSIS}

The existing flux switching permanent magnet linear generator (FSPMLG) essentially contains a translator mounted to a float or buoy that moves vertically with oceanic wave elevation and the stator usually contains some copper coils and permanent magnets as shown in Fig. 1, where the North and South poles of permanent magnets are indicated by red and green colors, respectively.

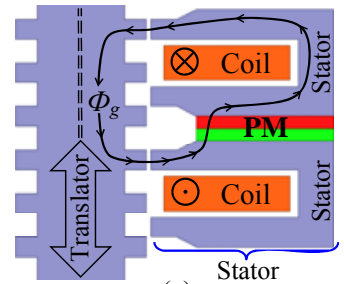

(a)

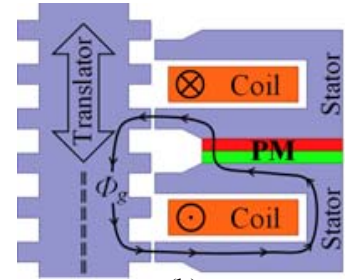

(b)
Fig. 1. Existing FSPMLG cross section: (a) at time $t_{1}$, and (b) at time $t_{2}$. 
Considering the upward direction of the translator at time $t_{1}$, the net flux $\Phi_{g}$ travels according to the direction shown by the arrows in Fig. 1(a). At time $t_{2}$, it aligns with the stator as shown in Fig. 1(b). The change in the direction of $\Phi_{g}$ occurs due to the flux switching in the stator, and the linear generator working by this principle is known as the FSPMLG. Fig 2(a) represents an FSPMLG submerged in the ocean for WEC. The magnetic flux density, $B$ of a conventional FSPMLG is simulated. It is found that $B$ reaches its maximum value, $B_{\max }$ for specific translator teeth positions. As the translator propagates in a periodic nature, there is also a periodic propagation of $B_{\max }$ in the translator. There are some regions in the translator where $B$ reaches a lower value, which can be observed in Fig. 2(b). Therefore, it is possible to minimize some of these regions from the translator.

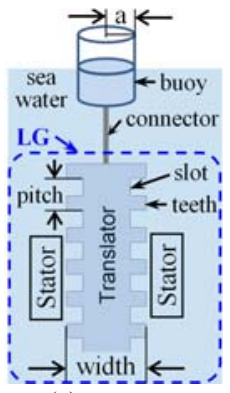

(a)

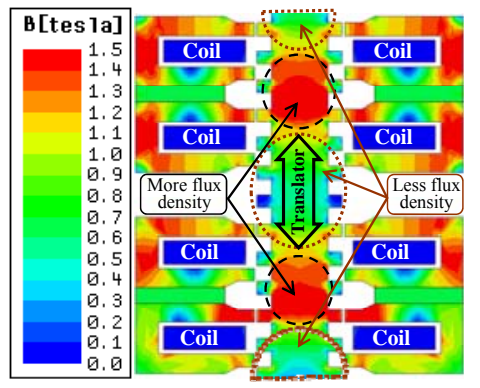

(b)
Fig. 2. (a) Conventional FSPMLG and (b) its magnetic flux density.

\section{Dynamic Model of the Oceanic Wave}

The oceanic wave has been considered sinusoidal for the analysis. The motion of the oceanic wave, $Z_{s}(t)$ can be expressed as:

$$
\begin{aligned}
& Z_{s}(t)=\frac{H_{w}}{2} \cos \left(\frac{2 \pi}{\lambda} x-K_{w} t\right) \\
& \text { where, } K_{w}=\sqrt{g k \tanh \left(k D_{s b}\right)}
\end{aligned}
$$

where $H_{w}$ is the vertical difference between the wave peak and wave trough, $\lambda$ is the wavelength, $x$ is the distance of wave propagation, $g$ is the gravitational acceleration, $k$ is the wave number, and $D_{s b}$ is the depth of ocean from water surface to sea bed. Theoretically, the buoy which is basically a float should follow the oceanic water surface, but practically not. The vertical displacement of the float is not the same as that of the water surface. There are two reasons which are liable, one is the mass of the float, and the other is the armature reaction. As the buoy is connected to the translator directly, the vertical acceleration, $a_{b}(t)$, displacement, $d_{b}$, and velocity, $v_{b}$ of the buoy/translator are related with the vertical displacement, $d_{s}$, and velocity, $v_{s}$ of the water surface as:

$$
a_{b}(t)=\frac{K_{f}\left[d_{b}(t)-d_{s}(t)\right]+R_{e q}\left[v_{b}(t)-v_{s}(t)\right]}{M_{f}+M_{w}}
$$

where

$$
K_{f}=\rho_{s} g \pi r^{2}
$$

where $\rho_{s}$ is the mass density of sea water, $g$ is the gravitational acceleration, $r$ is the cylinder radius, $R_{e q}$ is the combination of radiation and viscous resistances of sea water found from hydrodynamics analysis, $M_{f}$ is the mass of the float, $M_{w}$ is the additional mass due to sea water. Both the masses of the buoy and the translator contribute to the value of $M_{f}$. The acceleration of translator falls to a lower value for its higher mass that leads to lower average velocity according to (4).

\section{The Proposed STSSLG}

Two types of neodymium iron boron permanent magnets denoted by $\mathrm{N}_{1}$ and $\mathrm{N}_{2}$ with magnetic coercivity of $h_{c}=838\left(\mathrm{~N}_{1}\right)$, $939\left(\mathrm{~N}_{2}\right) \mathrm{KA} / \mathrm{m}$, remanence of $B_{\text {rem }}=1.13\left(\mathrm{~N}_{1}\right), 1.233\left(\mathrm{~N}_{2}\right) \mathrm{T}$. Relative permeability for the two magnets are almost similar. The copper winding with mild carbon steel $(0.27 \% \mathrm{C})$ is selected for the magnetic core as it has high magnetic saturation point, general availability and acceptable cost.

\section{A. Working Principle of the Proposed STSSLG}

Some of the magnetic flux lines travel through the supporting stator, which is illustrated in Figs. 3(a) and (b) instead of passing all of them through the translator as in the conventional FSPMLG. The net flux, $\Phi_{g}$, travels from the permanent magnet is split into two flux components: $\Phi_{t}$ traveling through the split translator shown by the blue arrows and the remaining flux, $\Phi_{s}$, passing through the secondary stator in one direction only (here downward). There is no flux switching in the secondary stator, rather in main stator only. Fig. 3(c) shows two equivalent secondary stator (SS) designs.

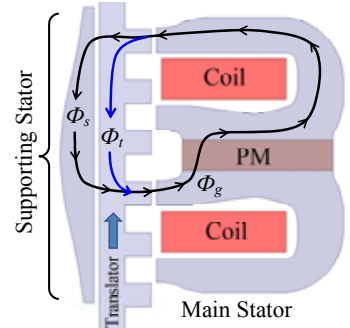

(a)

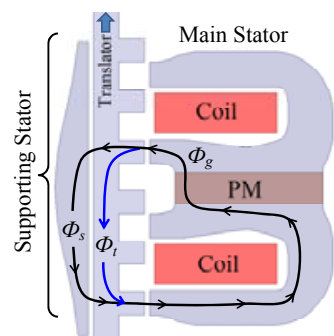

(b)

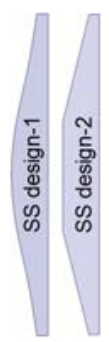

(c)
Fig. 3. Working principle of the proposed STSSLG: (a) at time $t_{1}$, (b) at time, $t_{2}$, and (c) two different equivalent designs of the secondary stator.

\section{B. Electricity Generation of the STSSLG}

The induced phase voltage in a winding of the proposed generator $E_{g}$ is

where

$$
E_{g}=\mathrm{K}_{\mathrm{m}} \cos \left(\frac{d_{b}}{\tau_{p}} \pi\right) v_{b}(t)
$$

and $B_{g}, N_{\varphi}, v_{a v g}, W_{s e}$, and $\tau_{p}$ are the air gap flux density, turn number in a winding, average velocity of the translator, effective stator width, and translator pole pitch, respectively.

\section{Architecture and Stator Position Vector Diagram}

The magnetization curve of the steel core is shown in Fig. 4(a). The cogging force and force ripples that are liable for undesirable results and damage of linear generators can be minimized by the stator position vector diagram as shown in 
Fig. 4(b). The individual unit of the proposed linear generator is divided into four segments, namely, $S S_{i a}, S S_{i b}, S S_{i c}$, and $S S_{i d}$ where, $i=1,2,3$. Each of the segments is constructed by three sets of stators marked as red, green, and blue rounded rectangle as shown in Fig. 4(c). The dashed pink enclosed lines represent that each of the windings consists of two consecutive coils. In the 3-D Cartesian coordinate system, the direction of translator motion is along the $z$-axis. $S S_{i a}$ and $S S_{i b}$ as well as $S S_{i c}$ and $S S_{i d}$ are two pairs of vertical mirrors to each other and are coupled together to minimize cogging force enclosed by dashed blue rectangles as shown in Fig. 4(b). On the other hand, $S S_{i a}$ and $S S_{i b}$ are $90^{\circ}$ phase shifted from $S S_{i c}$ and $S S_{i d}$, respectively, to minimize force ripples that are enclosed rectangles of the red color. Each of the four segments has a $60^{\circ}$ phase shifted stator pair sets, namely, $S S_{i a}^{\prime}, S S_{i b}^{\prime}$, $S S_{i c}^{\prime}$, and $S S_{i d}^{\prime}$, are situated in the opposite side of the $z$-axis as shown in Fig. 4(c) to minimize the small force ripples.

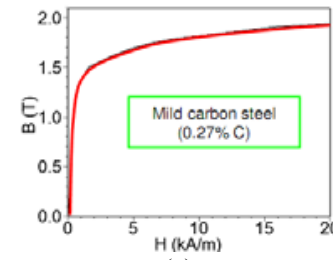

(a)

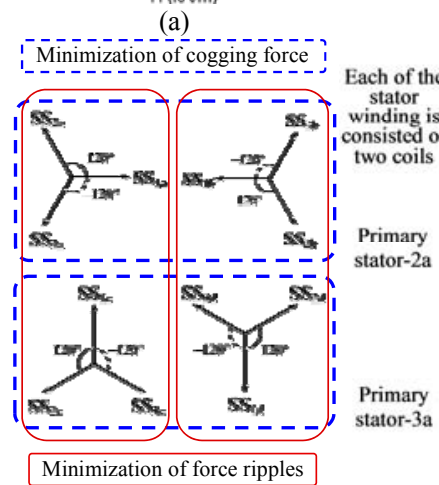

(b)

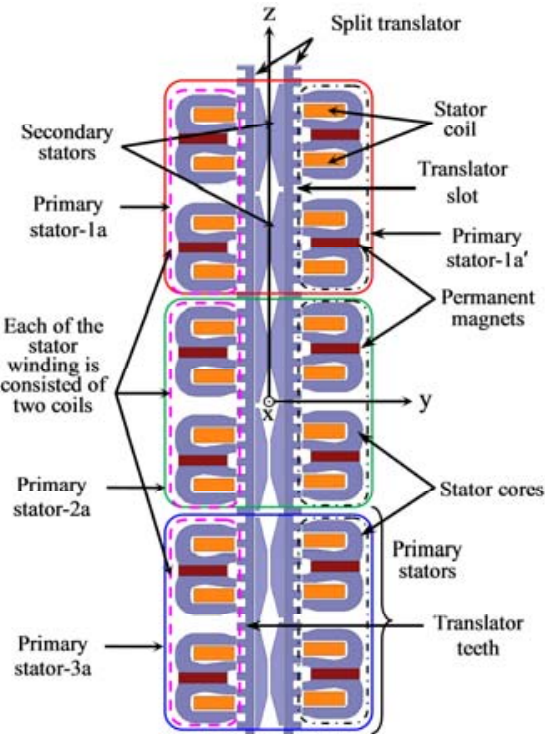

(c)
Fig. 4. (a) BH curve of the steel core, (b) stator position vector diagram, and (c) construction of the proposed STSSLG.

\section{Equivalent Circuit Diagram of the STSSLG}

Any one of the four segments of the STSSLG equivalent circuit is drawn in Fig. 5. $E_{1 a}, E_{2 a}$, and $E_{3 a}$ are the generated voltages of $S S_{i a}$, and $E_{l a}^{\prime}, E_{2 a}^{\prime}$, and $E_{3 a}^{\prime}$ are the generated voltages of $S S_{i a}^{\prime} . R_{a}$ is the armature resistance and $L_{a}$ is the inductance of a winding. The individual bridge rectifier is used to convert ac power into dc power connected to the load.

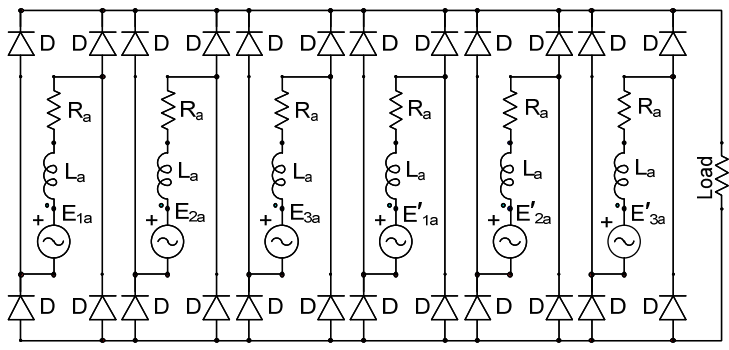

Fig. 5. Equivalent circuit diagram of a segment of the STSSLG.

\section{Simulation Results}

The mesh plot and magnetic flux lines of the proposed STSSLG are partially shown in Fig. 6 and the magnetic field strength and magnetic flux density are shown in Fig. 7 for a particular time.

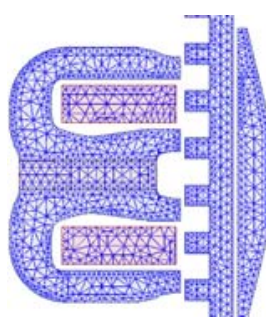

(a)

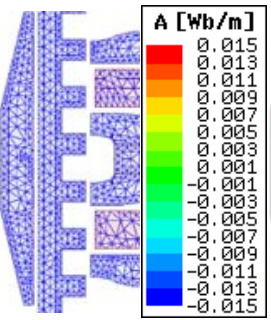

.
Fig. 6. (a) Mesh plot and (b) flux lines of the proposed STSSLG.

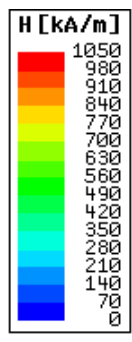

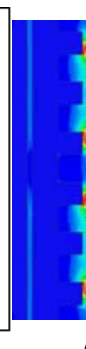

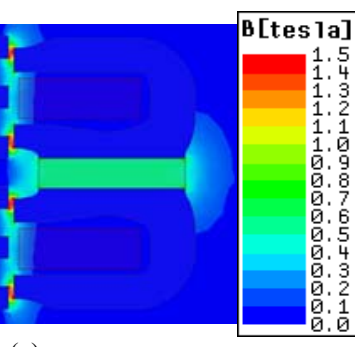

(a)

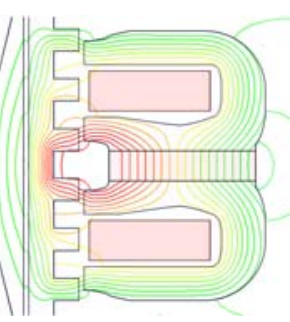

(b)
Fig. 7. (a) Magnetic field intensity and (b) flux density of the STSSLG.

The induced voltage, current, and power generated from a winding for the default condition are shown in Fig. 8. The generated power of different windings of $S S_{i a}$ and $S S_{i a}^{\prime}$ are shown in Fig. 9(a) and the rectified voltage, current, and power of this segment in Fig. 9(b). Figs. 10(a) and 10(b) show that the cogging forces and force ripples are canceled each other by using the stator position vector diagram.

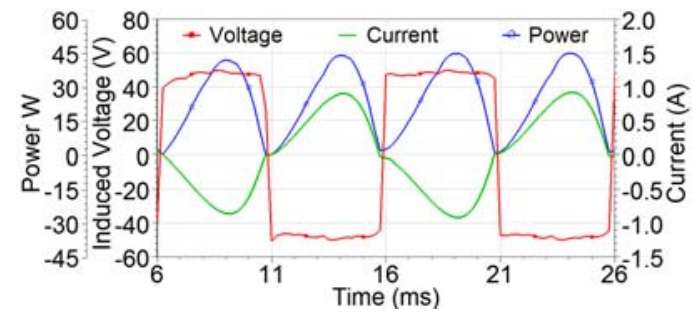

Fig. 8. Voltage, current, and power generation for two-cycle interval.

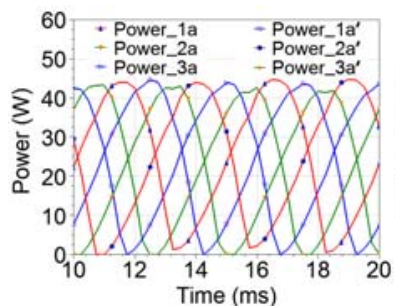

(a)

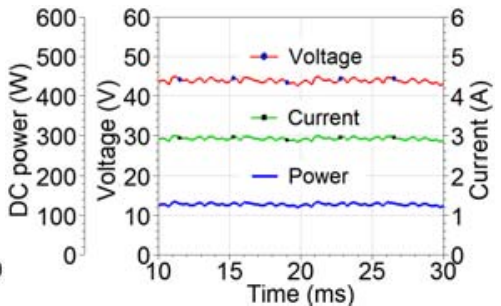

(b)
Fig. 9. (a) The generated power in windings of $\mathrm{SS}_{\mathrm{ia}}$. (b) The voltage, current, and power of $\mathrm{SS}_{\mathrm{ia}}$ after rectification. 


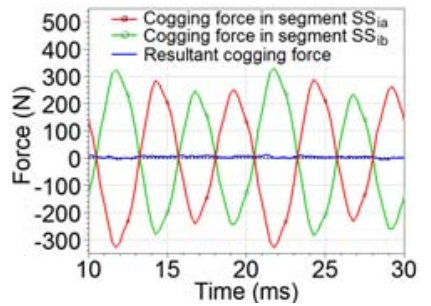

(a)

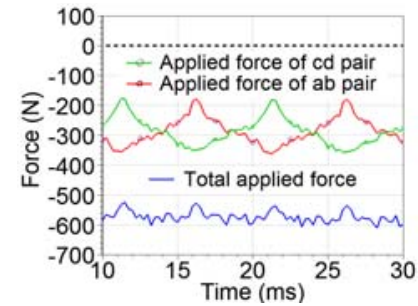

(b)
Fig. 10. Minimization of (a) the cogging force and (b) the force ripples.

The force components have been almost neutralized to each other because of proper cascading. The magnetic losses of a segment of the STSSLG are shown in Fig. 11(a). Fig. 11(b) shows the instantaneous power of a winding for different conventional and the proposed translators which are shown in Fig. 12(a).

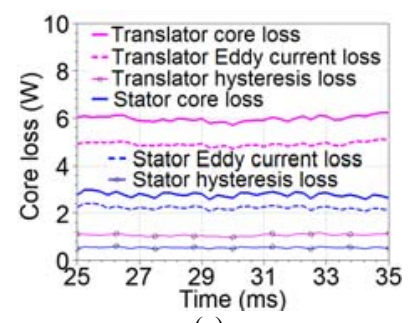

(a)

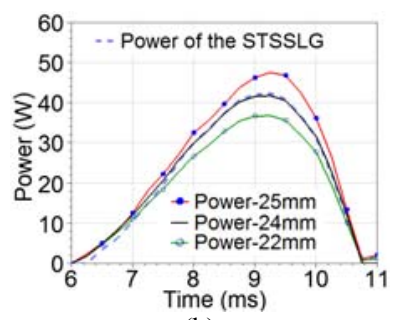

(b)
Fig. 11. (a) Core losses in the split translator and the secondary stator. (b) Power generation for different translators of the FSPMLG and the STSSLG.

Some parameters of a segment for load and translator speed variations are shown in Figs. 12 and 13, respectively. The efficiency, $\eta$ is calculated using $\left(\eta(\%)=\frac{P_{d c} \times 100 \%}{S_{t r}\left(F_{a r f}+F_{g a f}\right)}\right)$ considering the armature reaction force, $F_{a r f}$ only, where $S_{t r}$ denotes the translator speed, $P_{d c}$ denotes the dc power, and $F_{g a f}$ denotes the gravitational acceleration force. Tables I and II represent the common parameters and comparisons between FSPMLG and STSSLG.

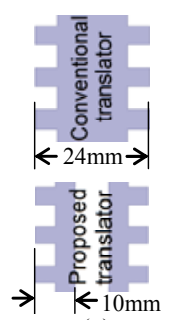

(a)

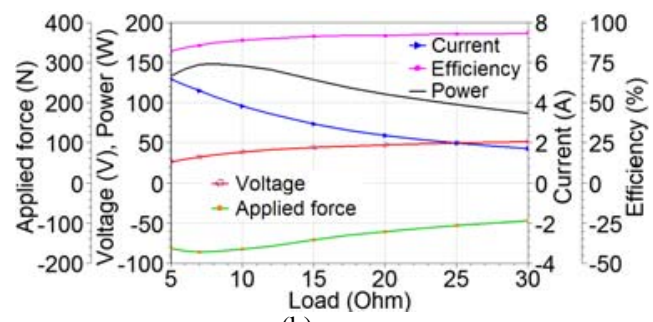

(b)
Fig. 12. (a) Equivalent width of the conventional and the proposed translator (b) Plot of five significant parameters for different load conditions.

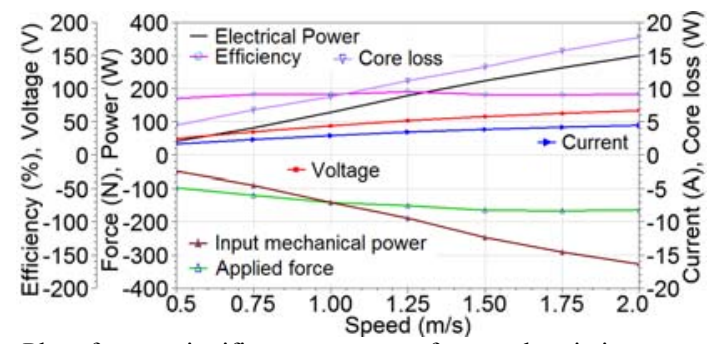

Fig. 13. Plot of seven significant parameters for speed variation.
COMMON PARAMETERS OF THE FSPMLG AND THE STSSLG

\begin{tabular}{lclc}
\hline \hline \multicolumn{1}{c}{ Name of the item } & value & \multicolumn{1}{c}{ Name of the item } & value \\
\hline Default translator speed $(\mathrm{m} / \mathrm{s})$ & 1 & Default load $(\Omega)$ & 15 \\
Translator tooth width $(\mathrm{mm})$ & 4.5 & Translator slot width $(\mathrm{mm})$ & 5.5 \\
Translator tooth/slot depth $(\mathrm{mm})$ & 5 & Translator length $(\mathrm{m})$ & 1.6 \\
Translator tooth pitch $(\mathrm{mm})$ & 10 & Stroke length $(\mathrm{m})$ & 0.8 \\
Turn number of copper coil (turn) & 130 & Thickness of PM $(\mathrm{mm})$ & 6 \\
Depth of the LG $(\mathrm{m})$ & 0.25 & Air gap $(\mathrm{mm})$ & 1 \\
Winding factor & 0.6 & Winding resistance $(\Omega)$ & 3 \\
Velocity of translator $(\mathrm{m} / \mathrm{s})$ & $0.5-2$ & Load resistance $(\Omega)$ & $5-30$ \\
Gravitational acceleration $\left(\mathrm{m} / \mathrm{s}^{2}\right)$ & 9.8 & Specific gravity & 7.87 \\
\hline \hline
\end{tabular}

TABLE II

COMPARISON OF THE CONVENTIONAL FSPMLG AND THE PROPOSED STSSLG Name of the item $\quad$ FSPMLG $\left(\mathrm{N}_{1}\right)$ STSSLG(N $)_{1}$ STSSLG(N $\left.\mathrm{N}_{2}\right)$

\begin{tabular}{lccc}
\hline Power generation of a unit $(\mathrm{kW})$ & 0.5 & 0.5 & 0.5
\end{tabular}

$\begin{array}{llll}\text { Translator width }(\mathrm{mm}) & 24 & 10 \times 2 & 7.5 \times 2\end{array}$

Mass of the translator $(\mathrm{kg}) \quad 40.6 \quad 31.74 \quad 20.665$

Required upward force $(\mathrm{N}) \quad 945.88 \quad 859.05 \quad 750.51$

\begin{tabular}{llll} 
Efficiency considering $F_{\text {gaf }}(\%)$ & 57.93 & 63.79 & 71.115 \\
\hline
\end{tabular}

\section{CONCLUSION}

From the simulation results it is observed that the conventional translator with $24 \mathrm{~mm}$ of width and the proposed split translator with $7.5 \mathrm{~mm}$ of width can generate the same amount of electrical power. On the other hand, it is shown clearly in (3) that the translator with lower mass results in higher acceleration/velocity and in (5) higher velocity generates more electricity. Using the stator position vector, the resultant cogging forces and force ripples have been effectively reduced, resulting in smooth dc power. The weight/mass of the proposed translator is almost half compared to the conventional one, which leads to increase $\eta$ by $13.185 \%$ of the STSSLG because of its improved dynamics for the same wave height and time period.

\section{REFERENCES}

[1] World Energy Council, Energy Report, 2014

[2] B. Drew, A. R. Plummer, and M. N. Sahinkaya, "A review of wave energy converter technology," Proc. Inst. Mech. Eng. A, J. Power Energy, vol. 223, no. 8, pp. 887-902, 2009.

[3] E. Tedeschi, M. Carraro, M. Molinas, and P. Mattavelli, "Effect of control strategies and power take-off efficiency on the power capture from sea waves," IEEE Trans. Energy Convers., vol. 26, no. 4, pp. 1088-1098, Dec. 2011.

[4] J. Zhang, H. Yu, Q. Chen, M. Hu, L. Huang, and Q. Liu, "Design and experimental analysis of ac linear generator with Halbach PM arrays for direct-drive wave energy conversion," IEEE Trans. Appl. Supercond., vol. 24 , no. 3 , article 0502704 , Jun. 2014

[5] J. A. García-Alzórriz, J. Grau, R. Córdoba, and J. Muela, "A novel double-sided flat rectangular linear permanent magnets synchronous generator for sea wave energy application," in Proc. 7th Int. Conf. Electric. Electron. Eng., ELECO Bursa, 2011, pp. I-248-I-252.

[6] O. Farrok, M. R. Islam, M. R. Islam Sheikh, Y. Guo, J. Zhu and W. Xu, "A novel superconducting magnet excited linear generator for wave energy conversion system," IEEE Trans. Appl. Supercond., vol. 26, no. 7, article 6207105, Oct. 2016.

[7] S. W. Youn, J. J. Lee, H. S. Yoon, and C. S. Koh, "A new cogging-free permanent-magnet linear motor," IEEE Trans. Magn., vol. 44, no. 7, pp. 1785-1790, Jul. 2008.

[8] L. Huang, H. Yu, M. Hu, J. Zhao, and Z. Cheng, "A novel fluxswitching permanent-magnet linear generator for wave energy extraction application," IEEE Trans. Magn., vol. 47, no. 5, pp. 1034-1037, May 2011.

[9] L. Huang, H. Yu, M. Hu, C. Liu, and B. Yuan, "Research on a tubular primary permanent-magnet linear generator for wave energy 
conversions," IEEE Trans. Magn., vol. 49, no. 5, pp. 1917-1920, May 2013.

[10] J. K. H. Shek, D. E. Macpherson, M. A. Mueller, "Experimental verification of linear generator control for direct drive wave energy conversion," Renewable Power Generation, IET, vol. 4, no. 5, pp. 395403, Sep. 2010.

[11] L. Huang, J. Liu, H. Yu, R. Qu, H. Chen, and H. Fang, "Winding configuration and performance investigations of a tubular superconducting flux-switching linear generator," IEEE Trans. Appl. Supercond., vol. 25, no. 3, article 5202505, Jun. 2015.

[12] S. R. Huang, H. T. Chen, C. H. Chung, C. Y. Chu, and G. C. Li, "Multivariable direct-drive linear generators for wave energy," Applied Energy, vol. 100, pp. 112-117, Dec. 2012. 